\title{
Obesity - a Reluctance to Treat?
}

\author{
Jocelin I. Hall \\ King's College London School of Medicine, London, UK
}

The World Health Organisation (WHO) has reported the ever increasing obesity problem, with projections for 2015 suggesting 700 million adults being obese [1]. Despite being a relatively new field, obesity management has seen exciting developments in both surgery and medicine. However, it remains over-looked by most medical school curriculum. With most students destined to work in primary care should we be concerned that a gap in obesity education will result in a future reluctance to offer treatment and/or referral to specialist services?

Studies have found that, despite doctors being aware of the increased health risks associated with obesity and having an interest in the management of the condition, far fewer actually initiate an intervention in their patients [2]. The reasons behind their reluctance are unclear. Attitudes to obesity seem partially to blame. A 1985 study of 100 medical students examined their initial reaction to an obese person: $59 \%$ were negative, with the most common response $(22 \%)$ being disdain or disgust. The students perceived morbidly obese people as 'unpleasant, worthless and bad' [3]. This cohort of students have long since graduated, and, now in practice, it might be expected they would no longer hold such opinions. However, a recent study found $50 \%$ of doctors asked viewed their obese patients as 'awkward, unattractive, ugly, and noncompliant' while $30-45 \%$ described them as 'weak-willed, sloppy, or lazy' [4]. It would appear that the practice of medicine does not dispel the prejudices of youth. With these attitudes it is perhaps unsurprising that physicians are reluctant to engage in weight loss management with their patients [5].

Negative physician attitudes and stigma may be a barrier to obesity management, but the problem appears more complex and is exacerbated by an apparent lack of understanding of the aetiology of obesity amongst the medical profession. Most experts in the field support a strong genetic influence in the development of obesity [6]. Nevertheless, medical practitioners from other specialities are more likely to rate behavioural issues as the primary cause. A UK based study examined the beliefs of 89 general practitioners finding them to adhere to a 'victim blaming model' where they suggested both cause and solution to obesity were controllable by the patient [7].

The lack of understanding of the condition has led to physicians currently practising reporting feeling ill-prepared by their medical training for management of patients with obesity. Fogelman et al recently questioned 510 family physicians and reported that $72 \%$ felt ill-prepared to tackle obesity and considered the treatment they offered to be only of limited efficacy [8]. Medical students seem to be encountering similar difficulties. Despite acknowledging that it will be their clinical responsibility to counsel their obese patients, those asked have expressed a lack of satisfaction with the training they have received to tackle this task; Swift et al. [9] indicated that the students' concerns reflect their insufficient knowledge.

The effect of current limited understanding of obesity and negative attitudes to obese patients appears to be a reluctance to treat. Most physicians appear to view intervention as futile; only $22 \%$ of physicians asked believed long-term maintenance of weight loss was possible in obese patient groups [4]. Most interventions in primary care appear to be medical advice which Fogelman et al. [8] found in $95 \%$ of cases to be increasing physical activity. However, the doctors seemed less keen to explore more radical treatment options. Only 4\% recommended using regular anti-obesity drug therapy to their patients, and only $66 \%$ knew the indications of these drugs [8]. A separate study reported that only $23 \%$ of primary care physicians would recommend a patient for surgical evaluation if they met the criteria, despite it being the most effective longterm management of the condition [4].

This poor understanding of, and lack of preparation to deal with, the condition is worrying. Virtually all doctors, regardless of speciality, will be encountering obese patients and physicians may be unwilling to discuss weight management with their patients even though obesity counselling is often an important part of management of any obese patient. With the huge impact obesity has on both morbidity, mortality and cost

\section{KARGER}

Fax +497614520714

Information@Karger.de

www.karger.com (c) 2010 S. Karger GmbH, Freiburg

Accessible online at:

www.karger.com/ofa 
to the healthcare service, it is important that changes are made and that incoming medical practitioners are equipped with the necessary knowledge to tackle this chronic condition.

Dedicated education concerning the development and management of obesity improves student knowledge. Evidence indicates that a surgical rotation with speciality services in bariatric surgery improves students' understanding of the condition compared to time spent with any other surgical speciality [10]. However, it will not be possible for all medical students entering medical school to complete a rotation with the bariatric surgeons and, as obesity is not confined to one clinical speciality, dissemination of information concerning the condition in other contexts needs to be explored.

In the USA the National Heart, Lung, and Blood Institute (NHLBI) produced a working group report on competencies for overweight and obesity identification, prevention, and treatment as well as outlining recommendations for undergraduate, graduate and continuing medical education. The group identified the role of healthcare professionals in health promotion, citing the Institute of Medicine recommendation that prevention of obesity should be encouraged in children by tracking patients' BMI, providing evidence-based counselling, and having the healthcare team act as role models [11]. At an undergraduate level they suggested education on obesity should occur throughout the duration of the medical degree programme by a variety of teaching methods including 'lectures, case studies, small-group discussions, role plays, standardized patients, and problem-based learning across basic-science courses such as biochemistry and clinical training experiences such as ambulatory care rotations', that the education should be multidisciplinary, focusing on both the behavioural and biological aetiology of the condition, and that students should be taught to screen for obesity as part of their routine clerking [12]. These are American recommendations but the approach is equally applicable in European medical education. Currently, positive steps are being taken in UK medical schools to improve student knowledge. These include: the integration of health promotion into the undergraduate course, as this is an ideal arena for students to be provided with the knowledge and skills to tackle the behavioural aspects of obesity [13]; the provisions of optional topics on obesity available as part of the student-selected components/options in the medical course; and the availability of intercalated BSc programmes incorporating modules on obesity [14]. However, with two of the three steps described being optional rather than core components of the medical degree, greater emphasis needs to be placed on educating all medical students, and this should be reinforced through further training. Those already in practice should be encouraged to address the obesity amongst their patient groups. They should be advised to track patients' BMI to identify those at risk as well as to offer opportunistic lifestyle advice or more pro-active measures of referral to an exercise specialist both of which have been identified as having a positive effect on patient behaviour [15] and being cost-effective in publicly funded healthcare systems such as the UK [16]. Further training regarding the indications for pharmacological and surgical intervention in obese patients should be available, and there should be greater support for clinicians, particularly those in primary care, when initiating pharmacological therapy or referring for surgery.

\section{References}

1 World Health Organisation: Obesity and Overweight. Available from www.who.int/mediacentre/ factsheets/fs311/en/index.html (accessed January 17, 2010).

2 Kristeller JL, Hoerr RA: Physician attitudes toward managing obesity: differences among six specialty groups. Prev Med 1997;26:542-549.

3 Blumberg P, Mellis LP: Medical students' attitudes toward the obese and morbidly obese. Intl J Eat Disord 1985;4(2):169-175.

$\checkmark 4$ Foster GD, Wadden TA, Makris AP, Davidson D, Swain Sanderson R, Allison DB, Kessler A: Primary care physicians' attitudes about obesity and its treatment. Obes Res 2003;11: 168-1177.

$\checkmark 5$ Hebl MR, Xu J: Weighing the care: physicians' reactions to the size of a patient. Int J Obes Relat Metab Disord 2001;25:1246-1252.

6 Bray GA, York B, DeLany J: A survey of the opinions of obesity experts on the causes and treatment of obesity. Am J Clin Nutr 1992;55: 151S-154S.

$>7$ Ogden J, Bandara I, Cohen H, Farmer D, Hardie J, Minas H, Moore J, Qureshi S, Walter F, Whitehead MA: General practitioners' and patients' models of obesity: whose problem is it? Patient Educ Cousel 2001;44:227-233.
8 Fogelman Y, Vinker S, Lachter J, Biderman A, Itzhak B, Kitai E: Managing obesity: a survey of attitudes and practices among Israeli primary care physicians. Int J Obes 2002;26:1393-1397.

9 Swift JA, Sheard C, Rutherford M: Trainee health care professionals' knowledge of the health risks associated with obesity. J Hum Nutr Diet 2007;20: 599-604.

10 Banasiak M, Murr MM: Medical school curricula do not address obesity as a disease. Obes Surg 2001; 11:677-679.

11 Institute of Medicine (IOM): Preventing Childhood Obesity: Health in the Balance. Washington, D.C., The National Academy Press, 2005. Cited in: National Heart Lung and Blood Institute. Working Group Report on Competencies for Overweight and Obesity Identification, Prevention, and Treatment. May 3-4, 2005. Available from www.nhlbi. nih.gov/meetings/workshops/overweight/report.htm (accessed February 6, 2010).

12 National Heart Lung and Blood Institute: Working Group Report on Competencies for Overweight and Obesity Identification, Prevention, and Treatment. May 3-4, 2005. Available from www.nhlbi. nih.gov/meetings/workshops/overweight/report.htm (accessed February 6, 2010).
13 Wylie A, Thompson S: Establishing health promotion in the modern medical curriculum: a case study. Medical Teacher 2007;29:766-771.

14 King's College School of Medicine: Endocrinology Programme Information. 2010. Available from www.kcl.ac.uk/schools/medicine/ugstudy/curriculum/intercalated/programmes/endo/programme. html (accessed February 6, 2010).

15 Hillsdon M, Foster C, Cavill N, Crombie H, Naidoo B: The Effectiveness of Public Health Interventions for Increasing Physical Activity among Adults: A Review of Reviews, 2nd ed. London, Health Development Agency, 2005.

16 Barker Y for the Department of Health: Learning from LEAP - a report on the Local Exercise Action Pilots. Available from www.dh.gov.uk/dr_consum_dh/groups/dh_digitalassets/@dh/@en/documents/digitalasset/dh_063822.pdf (accessed March 24, 2010). 